\title{
EFFECTIVENESS OF DEXAMETHASONE FOR PREVENTION OF INTRAOPERATIVE SHIVERING IN CAESAREAN DELIVERY UNDER SUBARACHNOID BLOCK.
}

\author{
Pradhan $R^{1^{*}}$, Mishra $S K^{2}$, Khanal $K^{3}$, Regmi $G^{1}$
}

\begin{abstract}
Affiliation
1. Lecturer, Department of Anesthesia and Critical care, Birat Medical College and Teaching Hospital.

2. Lecturer, Department Obstetrics and Gynecology, Birat Medical College and Teaching Hospital.

3. Consultant, Department of Anesthesia and Critical care, Medical College and Teaching Hospital.
\end{abstract}

\section{ARTICLE INFO}

Received : 28 November, 2019
Accepted : 06 January, 2020
Published : 30 June, 2020

(C) Authors retain copyright and grant the journal right of first publication with the work simultaneously licensed under Creative Commons Attribution License CC - BY 4.0 that allows others to share the work with an acknowledgment of the work's authorship and initial publication in this journal.

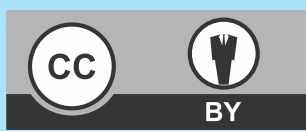

ORA 158

DOI: https://doi.org/10.3126/bjhs.v5i1.29615

\author{
* Corresponding Author \\ Dr. Roshan Pradhan \\ Lecturer \\ Department of Anesthesiology and Critical Care \\ Birat Medical College and Teaching Hospital \\ Email:drroshanpradhan@gmail.com \\ ORCID ID: https://orcid.org/0000-0002-0600-4446
}

\section{Citation}

Pradhan R, Mishra SK, Khanal K, Regmi G. Effectiveness of Dexamethasone for Prevention of Intraoperative Shivering in Caesarean Delivery Under Subarachnoid Block at Birat Medical College and Teaching Hospital, Morang, Nepal. BJHS 2020;5(1)11. 927-931.

\section{ABSTRACT \\ Introduction}

Shivering is frequently seen after subarachnoid block. Subarachnoid block impairs the thermoregulation system by inhibiting tonic vasoconstriction with redistribution of blood flow and core heat from the trunk to the peripheral tissue.

Intraoperative shivering leads to increase in oxygen consumption and carbon dioxide production. This causes an increase in heart rate, blood pressure resulting in exacerbation of ischemic heart disease, increased risk of hypoxemia, intraocular pressure, intracranial pressure, metabolic rate, lactic acidosis, pain at the surgical site and discomfort to the patient.

\section{Objective}

To assess the effectiveness of Dexamethasone in preventing intraoperative shivering in patients of cesarean delivery under subarachnoid block.

\section{Methodology}

This was a hospital based prospective, comparative, cross sectional study which was conducted from February 2019 to July 2019 among 88 pregnant patients of age group 18 to 35 years old, American Society of Anesthesiologists (ASA) physical status 1 and 2, posted for elective or emergency caesarean delivery at Birat Medical College and Teaching Hospital (BMCTH). Operation room temperature was recorded by a wall thermometer and maintained during surgery between 20 to 25 degree Celsius and intravenous fluids were kept at this temperature. Patients were divided into two equal groups. Group S (study group) patients received $2 \mathrm{ml}$ or $8 \mathrm{mg}$ of dexamethasone IV (As a premedication before giving subarachnoid block) while group $C$ (control group) patients received $2 \mathrm{ml}$ of normal saline. If the patients shivered according to classification of shivering, the prophylaxis was regarded as ineffective.

\section{Results}

Patients undergoing caesarean delivery under subarachnoid block had significantly reduced ( $p$ value $=0.002$ ) intraoperative shivering who received prophylactic dexamethasone (group S).

\section{Conclusion}

The prophylactic use of $8 \mathrm{mg}$ i.v dexamethasone was significant in prevention of shivering in Nepalese population who underwent caesarean delivery under subarachnoid block.

\section{KEYWORDS}

Caesarean section, dexamethasone, shivering. 


\section{INTRODUCTION}

The most common obstetric surgery performed worldwide is caesarean section under subarachnoid block. Shivering is frequently seen during intraoperative periods under subarachnoid block. Subarachnoid block impairs thermoregulation by inhibiting tonic vasoconstriction and it causes redistribution of blood flow and core heat from the trunk to the peripheral tissue. These effects make the patients vulnerable to hypothermia which consequently leads to shivering. ${ }^{1,2}$ Shivering can be either thermogenic (associated with hypothermia) or non thermogenic (associated with pain modulation, surgical stress, etc). Therefore, effective prevention and treatment of shivering has become an essential step in maintaining perioperative comfort and decreasing shivering related complications.

Shivering is a natural response of the body to hypothermia which includes rhythmic contraction of muscles along with the release of various cytokines at surgical site. ${ }^{3}$ As such, shivering is the body's next step in heat preservation after peripheral vasoconstriction and a common challenging side effect of spinal anesthesia. ${ }^{4}$ Causes of shivering include pain, decrease in sympathetic activity, uncontrolled spinal reflexes, release of pyrogenic materials, adrenal suppression and hypothermia. ${ }^{5}$ Shivering is considered as the sixth most important problem of current clinical anesthesiology and up to a $56.7 \%$ incidence has been reported. ${ }^{6}$

Human body core temperature is one of the most important factors to maintain physiology of the body. ${ }^{7}$ Hypothermia during surgery leads to shivering which causes an increase in oxygen consumption and carbon dioxide production. ${ }^{8}$ This causes an increase in heart rate and blood pressure resulting in exacerbation of ischemic heart disease, increase risk of hypoxemia, increase inintraocular pressure, increase in intracranial pressure, increase metabolic rate, lactic acidosis, increase pain at the surgical site and discomfort to the patient.

Various pharmacological and non-pharmacological methods for the prevention of intraoperative shivering have been used so far. Accordingly, it is essential to keep the patient normothermic with non-pharmacological methods like warming the skin-surface and warming the administered fluid. Pharmacological methods of using drugs like Pethidine, Dexamethasone, Opioid agonist, Ondansatron, Clonidine, Anticholinergics and Tramadol are used to prevent and treat hypothermia as well as shivering whereas non-pharmacological methods like radiant heaters, increased ambient temperature, blankets and warm fluids are being used. Sedation, hypotension, hypertension, respiratory depression, nausea and vomiting are common side effects of opioid and non-opioid pharmacological treatment.,

Dexamethasone is frequently used for prevention of intraoperative shivering. It also prevents and treats intra and post-operative nausea, vomiting and shivering, promotes appetite, suppresses inflammation and acts as a good analgesic agent both intravenously or as an adjuvant to peripheral nerve blocks. ${ }^{9}$ Dexamethasone acts by reducing the gradient between the skin and core body temperatures with modification of the inflammatory responses and regulating immune responses. ${ }^{7}$

\section{METHODOLOGY}

This was a hospital based prospective, comparative and cross sectional study conducted at Birat Medical College and Teaching Hospital from February 2019 to July 2019. After informed written consent, 88 adult pregnancy belonging to American Society of Anesthesiologist physical status I and II of age group 18 to 35 years old, requiring elective or emergency caesarean section with no history of known physical and mental illnesses and any history of taking NSAIDs, antidepressants and psychotropics were included in this study. Similarly, patients who refused to participate, those with neuromuscular diseases, psychological disorder, hypo or hyperthyroidism, those with recent history of febrile illness, weighing more than $100 \mathrm{~kg}$, with known history of alcohol or substance abuse, those receiving vasodilators and medications likely to alter thermoregulation and patient with inadequate sensory blockade were excluded from the study.

Operation room temperature was recorded by a wall thermometer and maintained between 20 to 25 degree during surgery and intravenous fluids was also kept in the same temperature. Patients were divided into two equal groups. The process of division of the two groups was masked and was kept blind to the researcher and the subject. Separate numbers were used to allocate various subjects between the groups. Group S patients received $2 \mathrm{ml}$ or $8 \mathrm{mg}$ of intravenous dexamethasone (as a pre-medication given 10 minutes before subarachnoid block) while group $C$ patients received $2 \mathrm{ml}$ of normal saline (10 minutes before subarachnoid block). All the patients were premedicated with intravenous aciloc $50 \mathrm{mg}$ and perinorm $10 \mathrm{mg}$. Patients received $10 \mathrm{ml} / \mathrm{kg}$ of Ringer lactate solution before subarachnoid block to prevent intraoperative hypotension (20\% decreases from baseline blood pressure. Subarachnoid block was given at L3/4 or L4/5 interspaces with Bupivacaine $0.5 \%$ heavy, $2.1 \mathrm{ml}$ was injected using a $25 \mathrm{G}$ Quincke spinal needle. All patients were connected to a monitor for monitoring of heart rate, non-invasive blood pressure, oxygen saturation and were recorded at the following interval: baseline, every 5 min intraoperatively and at the end of surgery. All the patients were observed for intraoperative shivering and were classified according to its grading.

\section{Classification of shivering ${ }^{6}$}

$0=$ no shivering, $1=$ =Piloerection or peripheral vasoconstriction, 2 = Muscular activity in only one muscle group, 3= Muscular activity in more than one muscle but not generalized, 4= Shivering all over the body.

The prophylaxis was regarded as ineffective and intravenous tramadol $0.5 \mathrm{mg} / \mathrm{kg}$ was given to the patients who had shivering according to classification of shivering. 
The acceptable error (type I error) of the study was 5\% with $80 \%$ of power of study. Previous study conducted by Desai et al. ${ }^{1}$ had shown that prevalence of shivering in the study group was $44 \%$ and in the control group was $37 \%$. The sample size was calculated as 88 population.

$\mathrm{N}=2(\mathrm{z} 1-\alpha / 2-z 1-B)^{2} \mathrm{pq} /\left(\mathrm{p}_{1}-\mathrm{p}_{2}\right)^{2}$

Where, $p=p_{1}-p_{2} / 2$

Data was entered in MS excel and analyzed by IBM SPSS version 23. Continuous data was presented as mean and standard deviation while categorical data was presented as the frequency and percentage. Significance was tested using chi-square test.

\section{RESULTS}

The two groups were similar in terms of demographic parameters (Table 1 ). Intraoperative shivering was significantly reduced ( $p$ value $=0.002$ ) in patients who received dexamethasone (group $\mathrm{S}$ ) as compared to group $\mathrm{C}$. (Table 2)

\begin{tabular}{|c|c|c|c|c|}
\hline \multicolumn{2}{|c|}{ Demographic Criteria } & Group C & Group S & $P$ value \\
\hline \multicolumn{2}{|c|}{ Age (years) } & $23.64 \pm 3.278$ & $23.93 \pm 3.419$ & 0.496 \\
\hline \multicolumn{2}{|c|}{ Weight (kg) } & $58.07 \pm 5.797$ & $57.64 \pm 8.861$ & 0.492 \\
\hline \multicolumn{2}{|c|}{ Duration of surgery (min) } & $27.73 \pm 5.110$ & $27.05 \pm 4.357$ & 0.492 \\
\hline \multicolumn{2}{|c|}{ Height $(\mathrm{cm})$} & $157.2 \pm 7.1$ & $155.74 \pm 5.39$ & 0.495 \\
\hline \multirow[t]{2}{*}{ ASA } & 1 & $42(95 \%)$ & $40(90.9 \%)$ & 0.873 \\
\hline & 2 & $2(4.54 \%)$ & $4(9 \%)$ & 0.429 \\
\hline
\end{tabular}

Table 2: Incidence of shivering

\begin{tabular}{|c|c|c|c|}
\hline & No $(\mathbf{n}=44)$ & Yes $(\mathbf{n}=44)$ & P value \\
\hline Group C & $28(63.6 \%)$ & $16(36.4 \%)$ & \multirow{2}{*}{0.002} \\
\cline { 1 - 3 } Group S & $40(90.9 \%)$ & $4(9.1 \%)$ & \\
\hline
\end{tabular}

Table 3: Different grades of shivering

\begin{tabular}{ccc} 
Shivering score & Group C & Group S \\
\hline 0 & $28(63.6 \%)$ & $40(90.9 \%)$ \\
\hline 1 & $6(13.6 \%)$ & $1(2.3 \%)$ \\
\hline 3 & $8(18.2 \%)$ & $0(0.0 \%)$ \\
\hline 4 & $1(2.3 \%)$ & $2(4.5 \%)$ \\
\hline
\end{tabular}

$P=0.001$ (statistically significant, using Fisher's Exact Test).

Table 4: Incidence of nausea and vomiting
\begin{tabular}{|l|l|l|l|}
\hline & No (n=40) & Yes (n=40) & P value \\
\hline Group C & $41(93.2 \%)$ & $3(6.8 \%)$ & 0.645 \\
\hline Group S & $42(95.5 \%)$ & $2(4.5 \%)$ & \\
\hline
\end{tabular}

Table 5: Incidence of hypotension
\begin{tabular}{|l|c|c|c|}
\hline & No (n=40) & Yes (n=40) & P value \\
\hline Group C & $37(84.1 \%)$ & $7(15.9 \%)$ & 0.334 \\
\cline { 1 - 3 } Group S & $40(90.9 \%)$ & $4(9.1 \%)$ & \\
\hline
\end{tabular}

\section{DISCUSSION}

Maintaining a normal body temperature is one of the important functions of the autonomic nervous system in homeothermic mammals like in human beings as cellular and tissue dysfunction become evident at even minor deviations from normal core body temperature $\left(36.5-37.5{ }^{\circ} \mathrm{C}\right) .{ }^{10}$ Perioperative shivering is one of the most common and unwanted complications after subarachnoid block. During subarachnoid block, there is internal redistribution of heat from central to peripheral tissue due to sympathetic block and peripheral vasodilation. As a result, there is failure of thermoregulatory vasoconstrictive effect below the level of subarachnoid block resulting in increase in heat loss from the body which leads to shivering. Shivering is a natural response of the body to hypothermia. Various pharmacological and non-pharmacological methods for control of shivering have been effectively used so far. It is essential to keep the patient normothermic with nonpharmacological methods like warming the skin-surface and warming the administered fluid.

In the present study, prophylactic use of intravenous dexamethasone was effective in preventing the incidence of intraoperative shivering in 40 patients $(90.9 \%)$ and only 4 patients (9.1\%) had shivering as compared to the control group where 16 patients $(36.4 \%)$ had intraoperative shivering. The findings of the present study were similar to Hossain et al. who had concluded that patients who had received intravenous dexamethasone experienced a significantly lower incidence of intraoperative shivering compared to placebo group ( $15 \%$ versus 55\%, p<0.05). ${ }^{11}$

In a randomized trial by Solhpour et al. prophylactic use of dexamethasone combined with meperidine was significantly effective in prevention of shivering during spinal anesthesia which was similar to the findings of our present study. ${ }^{12}$

Gholami et al. had shown no significant differences between three groups of dexamethasone, pethidine and normal saline in reducing shivering after spinal anesthesia in caesarean delivery. However, clinical complications 
like nausea, vomiting and headache were lower in dexamethasone group. ${ }^{13}$

In a study by Entezarias et al., nineteen cases (47.5\%) in placebo group compared to only four cases (10\%) in dexamethasone group had postoperative shivering and the difference between the two groups was significant. ${ }^{7}$ Similary, in the present study, only four cases $(9.1 \%)$ had shivering after prophylaxis with dexamethasone compared to 16 cases (36.4\%) in control group. This finding was statistically significant $(p=0.002)$.

Azeem et al. had conducted a study on patients undergoing transurethral resection of the prostate under spinal anesthesia where prophylactic dexamethasone was as effective as pethidine in reducing the incidence and severity of shivering postoperatively. ${ }^{8}$ This result was in agreement with the findings of the present study.

In contrast to the present study, Vinathi et al. had conducted a study where Dexamethasone, ketamine and tramadol were equally effective in preventing postanaesthetic shivering due to hypothermia after general anesthesia. ${ }^{14}$

In a study by Desai et al. intravenous dexamethasone when combined with ondansetron was effective in prevention of intraoperative nausea and vomiting observed due to hypotension following subarachnoid block. ${ }^{1}$ In the present study though the incidence of hypotension was markedly reduced in the study group compared to the control group (90.9\% vs $84.1 \%$ ) there was no significant difference in the incidence of nausea and vomiting among the both groups.

Song et al. conducted a comparative study between dexamethasone and ramosetron in patients undergoing thyroid surgery where ramosetron was superior to dexamethasone for reducing nausea, antiemetic consumption and the severity of nausea but dexamethasone was superior to ramosetrosetron in reducing the incidence of shivering. ${ }^{15}$ This result was similar to the present study

\section{REFERENCES}

1. Desai N.N DS, Sunasara N, Prajapti N. Comparative evaluation of effect of Ondansetron and Ondansetron with dexamethasone for prevention of nausea, vomiting \& shivering in patient of caesarean section under spinal Anesthesia. International Journal of Medicine Research. 2018;3(3):19-21. DOI: doi.org/10.22271/medicine

2. Moeen SM, Moeen AM. Intrathecal dexamethasone vs. meperidine for prevention of shivering during transurethral prostatectomy: a randomized controlled trial. Acta AnaesthesiologicaScandinavica. 2017;61(7):749-757. DOI: 10.1111/aas.12920

3. Ramalingaraju AVS, Siva RD, Neethika M. Post Operative Shivering: Prophylactic Effects of Ketamine and Pethidine, A Comparative Study in Tertiary Care Hospital. IOSR Journal of Dental and Medical Sciences (IOSR-JDMS). 2017;16(3):12-15. DOI: 10.9790/08531603041215

4. Lopez MB. Postanaesthetic shivering - from pathophysiology to prevention. Romanian Journal of Anaesthesia and Intensive Care. 2018;25(1):73-81. DOI: http://dx.doi.org/ 10.21454/rjaic. 7518.251.xum where dexamethasone was significantly effective in preventing intraoperative shivering.

\section{CONCLUSION}

We concluded that prophylactic $8 \mathrm{mg}$ of intravenous dexamethasone could effectively prevent the incidence and severity of intraoperative shivering in patients undergoing caesarean delivery under subarchnoid block.

\section{RECOMMENDATION}

We recommend that prophylaxis with dexamethasone provides highly effective prevention of intraoperative shivering, nausea and vomiting.

\section{LIMITATONS OF THE STUDY}

The limitation of our study was the short duration of surgery. It seemed that knowing the anti-shivering effects of the studied drugs in surgeries of longer duration would have been more practical and conclusive because of the high risk of hypothermia in such surgeries.

\section{ACKNOWLEDGEMENTS}

It is our great pleasure to express our heartily regards to all the respondents, OT staffs of Department of Anesthesiology of Birat Medical College and Teaching Hospital, Morang, Nepal, my seniors and my family for their continuous support, time and participation. Without them this study wouldn't have been possible.

\section{CONFLICT OF INTREST}

We declare no conflict of interest

\section{FINANCIAL DISCLOSURE}

None

5. Alijanpour E, Banihashem N, Maleh P.A, Majd H, Ropani MA. Prophylactic Effect of Oral Clonidine and Tramadol in Postoperative Shivering in Lower Abdominal Surgery. Open Journal of Anesthesiology. 2016;6:137-47. DOI: http://dx.doi.org/10.4236/ ojanes.2016.69023

6. Sagir O, Gulhas N, Toprak H, Yucel A, Begec Z, Ersoy O. Control of shivering during regional anaesthesia: prophylactic ketamine and granisetron. Acta AnaesthesiologicaScandinavica. 2007;51:44-9. DOI: 10.1111/j.1399-6576.2006.01196.x

7. Entezariasl M, Isazadehfar K. Dexamethasone for prevention of postoperative shivering: a randomized double-blind comparison with pethidine. International journal of preventive medicine. 2013;4(7):818-24. PMID: 24049601

8. El Bakry AA, Ibrahim ES. Prophylactic dexamethasone or pethidine for the prevention of postoperative shivering during transurethral resection of the prostate under spinal anesthesia. Ain-Shams Journal of Anesthesiology. 2016;09:349-52. DOI: 10.4103/1687-7934. 189102 
9. Gupta B. Role of Dexamethasone in Peri-operative Anesthesia Management: A Review of Literature. Anesthesiol Open J. 2017;2(2):33-9. DOI: 10.17140/AOJ-2-114

10. Vinathi GA, Latha VS. Efficacy and Potency of Dexamethasone In Comparison With Ketamine and Tramadol in the Prevention of PostOperative Shivering. IOSR Journal of Dental and Medical Sciences (IOSR-JDMS).17(4):66-72. DOI: 10.9790/0853-1704166672

11. Hossain MS, Rashid MM, Islam SA, Babu AR, Mandal MA. Dexamethasone for Prevention of Postoperative Shivering: A Prospective Clinical Study. KYAMC Journal. 2019;10(02):81-4. DOI: https://doi.org/10.3329/kyamcj.v10i2.42784

12. Solhpour A, Jafari A, Hashemi M, Hosseini B, Razavi S, MohseniG, Vosoughian M, Behnaz F, Nejad RA, Pourhoseingholi MA, Soltani F. A comparison of prophylactic use of meperidine, meperidine plus dexamethasone, and ketamineplus midazolam for preventing of shivering during spinal anesthesia: a randomized, double-blind, placebo-controlled study. Journal of Clinical Anesthesia 2016;34:12835. DOI: http://dx.doi.org/10.1016/j.jclinane. 2016.03.036
13. Gholami H, Moradi Y, Khazaei Z, Tehrani S. A comparison of the effect of dexamethasone and pethidine for prevention of shivering after spinal anesthesia in caesarean section: randomization clinical trial. Biomed Res Ther. 2018;5(9):2646-50. DOI: : 10.15419/ bmrat.v $5 i 9.473$

14. Vinathi GA, Latha VS. Efficacy and Potency of Dexamethasone In Comparison With Ketamine and Tramadol in the Prevention of PostOperative Shivering. IOSR Journal of Dental and Medical Sciences (IOSR-JDMS). 2018;17(4):66-72. DOI: 10.9790/0853-1704166672

15. Song YK, Lee C. Effects of ramosetron and dexamethasone on postoperative nausea, vomiting, pain, and shivering in female patients undergoing thyroid surgery. J Anesth. 2013;27(1):29-34. DOI: $10.1007 /$ s00540-012-1473-8 